\title{
Suggested Educational Units Using The Game-Oriented to İmprove the Coordination Skills of Primary Students
}

\author{
Harbach Brahim ${ }^{1}$, Senouci Abdelkrim ${ }_{4}^{2}$, Mokrani Djamel ${ }^{3}$, \\ Djourdem Benehiba \\ ${ }^{1234}$ Abdelhamid Ibn Bais Mostaganem University, ALGERIA \\ https://orcid.org/0000-0000-0000-0000 \\ Email: brahim.harbach@univ-mosta.dz \\ Type: Research Article (Received:30.05.2020 Accepted:24.10.2020)
}

\begin{abstract}
The aim of the study was to determine the effect of proposed educational units, by directed game, on the balance, compatibility, and speed of reaction of primary school pupils (9-12 years). We assumed that the units positively affect the development of balance, compatibility, and speed of reaction. We applied them on a sample of 26 students, divided into two groups experimental and control. We relied on an eight race test, a foot-to-foot balance test, and Nelson Kinetic Response. SPSS program was used in the statistical analysis of the data obtained. Finally, we concluded that there was an improvement in the quality of compatibility in the experimental sample.
\end{abstract}

Keywords: educational units, guided game, compatibility skills, primary school. 


\section{Introduction}

Good compatibility is one of the basic requirements for practicing motor skills, which is formed by muscle contractions, so that each joint muscle serving motor skills should contract and relax at the appropriate time, where harmonic exercises should be used to acquire and master the different movements and sport skills in a meaningful way, as difficult, complex and overlapping movements often need simplification and progression, and sometimes even fragmentation, for the learner to be able to perform it in its complex form as a complete skill later on.(Mustapha, O., 2013)Playing is an important educational medium, working to create children at this critical stage of human development, and one of the most vital and important activities for children's lives. It is a necessary learning experience through play that enables children to master skills and gain insights into cognitive, social, physical and psychological aspects, and therefore there is a close relationship between child intelligence and play.(Ahmed N, G., 2010) Playing is often described as an automatic activity that is not tied to external factors, and examples of play are from invertebrates to monkeys, so we need to classify playing activities into at least four categories, which need to be analyzed in at least four different sets of conditions. This is the random play that begins in early childhood, the regular semi-play that begins in the middle childhood, the regular play that appears with the late childhood, and the abstract play that accompanies adolescence.(Abdelhadi N., 2004) Learning by playing is a modern teaching technique, and children are the focus of learning, and play is a guided activity by children to develop their mental, physical, and emotional behaviors and abilities, while also making fun and fun, and the learning style by playing is to use play activities to gain knowledge, bring science principles closer to children, and extend their cognitive skills.(Harbech; B.,2020) Educational studies have demonstrated the importance of playing games in gaining knowledge and communication and interaction skills if they are best exploited and organized, and play is a pedagogical medium that works to a great extent to shape the personality of the child in its different dimensions, social outreach for more interaction with others, compulsory engagement in school education and integration with the school environment. It is also the key to building a child's productive personality by investing games in his or her economic and financial concepts. (Uskan, S., Bozkus, T., 2019; Harbach, $\mathrm{B}$, .2016) Despite efforts in this regard, physical education has not been as high as it is intended at the primary level for many reasons, and the goals set for physical education at this stage (9-12) are aimed at developing physical fitness and giving children the opportunity to express themselves and their potential, as far as possible The situation and situation require that appropriate solutions be chosen, in line with their mental and physical abilities in terms of their development and improvement. Based on some previous studies, Harbach B, and others 2018, the effectiveness of the teaching strategy of playing with the development of some physical and motor capabilities in secondary school students, and the study of Marwa Mohammed Ali Sulaiman, entitled the effectiveness of a guided play program in addressing the inadequacy of some cognitive abilities of kindergarten children. As mentioned above, the use of guided games is an important issue that has not received the attention of researchers in the sports field in its general capacity and in physical and sports activities in educational institutions in particular. Through the survey conducted by researchers within educational institutions and some field visits, it was noted that the physical and sports classes lacked the types of training that contributed to the development of the physical, professional and mental capacities of this group, which needed care and attention in the exercise of physical and sports activities. Researchers have been interested in using a training program using directed play and in learning its impact on some of the compatibility abilities of primary school students. 


\section{Method}

Research methodology: Researchers used the experimental method using two groups, one experimental and one control, to match the nature of the research.

Research and Sample: The research Society is 90 children between 9-12 years of school season 2018/2019 in a deliberate manner, and the research sample included 26 male pupils. A sample officer of 13 primary-year pupils was divided B and a teacher-led program was applied to them.

The two groups were chosen in the deliberate way, as the proposed units were applied to the experimental sample after being presented to a group of professors in the field of physical and sports education, sports training and movement sciences, and researchers performed the equivalence between the experimental and control eyes. This is by examining some variables that will affect the experimental variable of compatibility capabilities.

Research Tools: After getting acquainted with the methods of selecting samples, we now turn to some means of collecting information through questionnaire, interview and observation, and these three types can be relied upon by every specialist in his profession, whether that specialization is research science or social science, but it depends on the nature of the subject and the type of information to be collected.

Physical tests: One of the most important methods used in experimental research as the basis for objective evaluation is the most effective way to achieve accurate results, so researchers have relied on standardized tests that measure the compatibility of children on the research sample associated with the subject matter of study, and these tests have been presented to experts for arbitration, as follows:

\section{Test run in the form of the number eight :}

-Test objective: Measure student compatibility.

-Tools used: A person to determine the distance, my time to determine the time of each pupil, a dicameter bar.

- Working method: two persons are placed so that the distance between them is six metres, the child starts to run in the form of the number eight so that the child can lean on the two persons to determine the place where he or she changes direction, the child runs four sessions to determine the time of his or her choice.

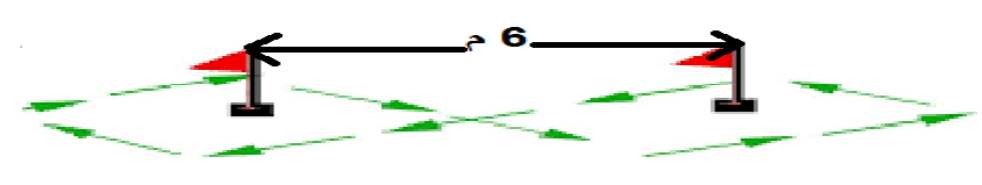

Figure 2. Shows the stages of running a run as 8

\section{The walking test is foot behind a foot :}

The purpose of the test: To measure the balance of the student. 
- Instruments used: timer, decameter tape, plotter, etc.

- Method of work: The distance of 6 meters is determined by plos, where the student stands at the first pad and hearing the whistle, the student starts to walk behind to stick to reach the second pad for the attempt to be correct, then we record the time for each student.

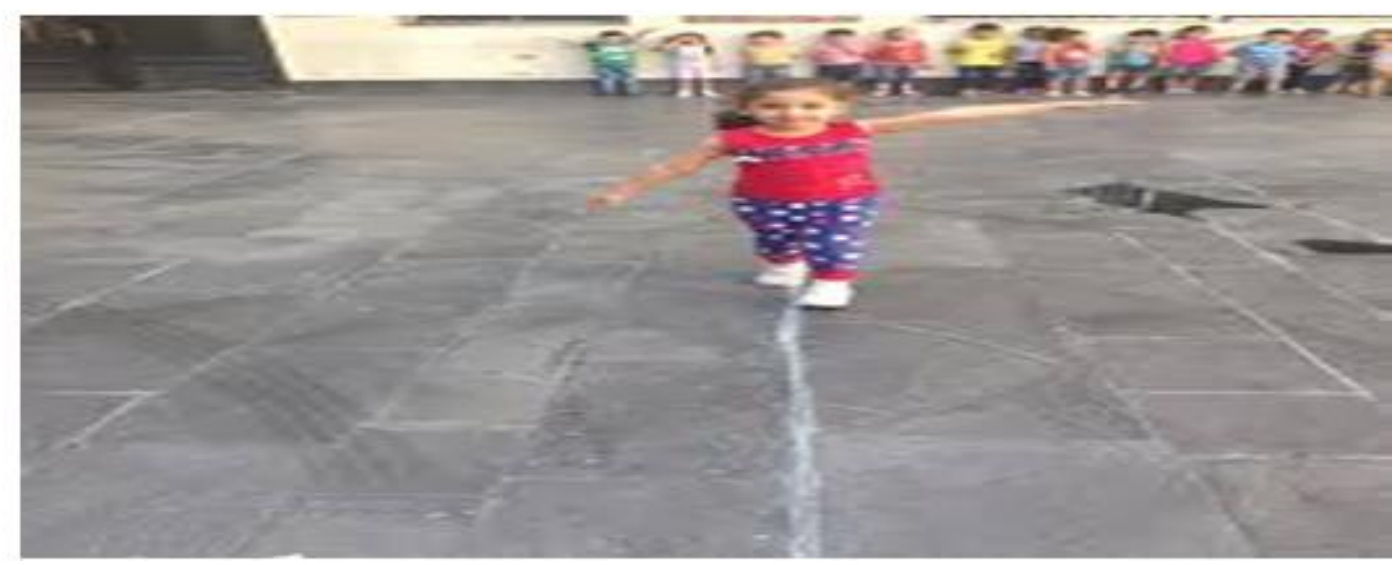

Figure 1. Shows how the foot-behind-the-foot walking is performed

\section{Nelson test for motor response:}

The objective of the test: to measure the student's reaction speed.

- Instruments used: chronometer, decameter, markers.

- The method of work: the student stands in front of the teacher who holds the chronometer with one of his hands, lifting it upwards, then quickly moves his arm, either to the left or to the right and at the same time executes the stopwatch, so that the student executes at full speed in the direction indicated by the teacher, and when he reaches the student at the end of the previously determined distance, which is a distance of $(6.4 \mathrm{~m})$ The teacher stops the stopwatch to record the time achieved by the student.

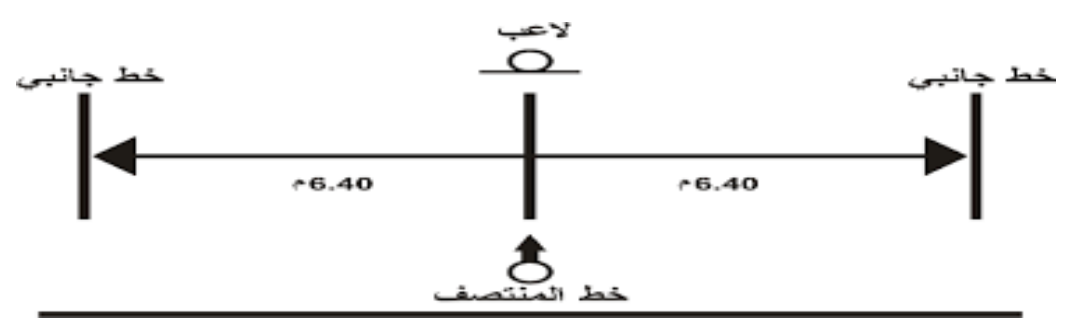

Figures 3. Shows how Nelson's kinetic response test is performed

\section{Suggested educational units:}

To achieve the objectives of this research and solve its problem, the researchers selected two samples, the first experimental and the second control, so that a set of tribal tests and proposed units would be applied to them, and these units were applied to the experimental sample, and these units contained a set of simplified games that would develop consensual skills, The total number of proposed units was 08 units at the rate of one teaching unit per week in two months. 


\section{A. foundations of the course development:}

The researchers constructed the proposed units on a scientific basis, selecting program content, movement activities and physical exercises, focusing on a group of games to improve certain harmonic abilities of the research sample. 08 units were placed at the rate of one educational unit per week within two months, to contain physical exercises And kinetic activities focused on the use of guided play, and program content included walking and balance exercises and games, running exercises and games, jumping exercises and games, exercises and compatibility of games with movement games.

The proposed modules are based on a well-established scientific basis that takes into account all aspects of pupils' development, especially with regard to the characteristics of late childhood, which are characterized by physical, psychological or social development and in which physical activity plays a significant role in this development.

\section{Results}

- Pre-testing for two sample searches:

Table 1. T-test results for the significance of differences between the means of the tribal tests for the two research samples: degree of freedom 42 at the .05 significance level.

\begin{tabular}{|c|c|c|c|c|}
\hline \multirow[t]{2}{*}{ Variables } & Experimental sample & control sample & \multirow{2}{*}{$\begin{array}{l}\text { Calculat } \\
\text { ed T }\end{array}$} & \multirow{2}{*}{$\begin{array}{l}\text { Tabular } \\
\mathrm{T}\end{array}$} \\
\hline & $\mathrm{SD}( \pm)$ & $\mathrm{SD}( \pm)$ & & \\
\hline
\end{tabular}

\begin{tabular}{lllllll}
\hline Length (m) & 1.4 & 0.03 & 1.41 & 0.02 & 1.16 & No sig \\
\hline Weight (kg) & 30.69 & 1.48 & $5^{31.0}$ & 1.24 & 0.68 & No sig
\end{tabular}

\begin{tabular}{|c|c|c|c|c|c|c|c|}
\hline $\begin{array}{l}\text { Running Test } \\
\text { (Compatibility) (s) }\end{array}$ & 18.29 & 1.01 & $3^{18.0}$ & 0.96 & 0.65 & & No sig \\
\hline $\begin{array}{ll}\text { Walking } & \text { test } \\
\text { (balance) (s) } & \end{array}$ & 15.41 & 2.12 & $6^{15.5}$ & 1.97 & 0.18 & 1.71 & No sig \\
\hline
\end{tabular}

\begin{tabular}{lrllllll}
\hline $\begin{array}{l}\text { Nelson } \\
\text { response }\end{array} \begin{array}{r}\text { kinetic } \\
\text { test }\end{array}$ & 2.43 & 0.26 & 2.39 & 1.18 & 0.5 & No sig \\
$($ reaction speed) $(\mathrm{s})$ & & & & &
\end{tabular}

\section{Discussion and analysis of pre and post test results for the two research samples:}

\section{First: Running test in the form of 8 (compatibility)}

Table 2. Results of the two tests for a running test in the form of 8 .

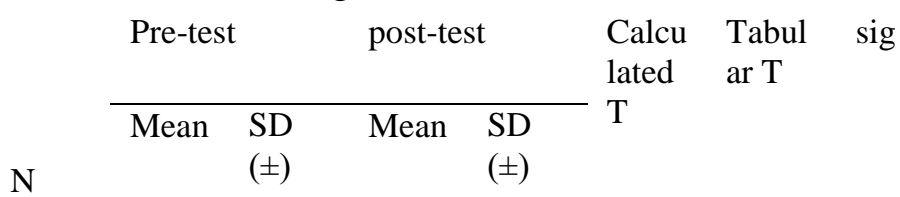

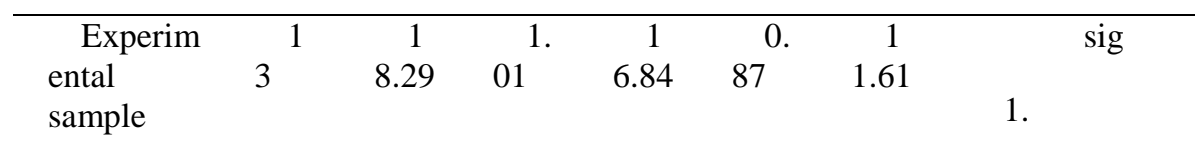


Brahim, and et al., Suggested educati... IntJSCS, 2020; 8(2):192-200

$\begin{array}{ccccccccc}\text { Control } & 1 & 1 & 0 . & 1 & 0 . & 1 . & 78 & \text { No sig } \\ \text { sample } & 3 & 8.03 & 96 & 7.91 & 77 & 61 & & \end{array}$

\section{Second: the test of walking feet behind the feet (balance):}

Table 3. The results of the pre and post tests the walking test presented behind the feet (balance).

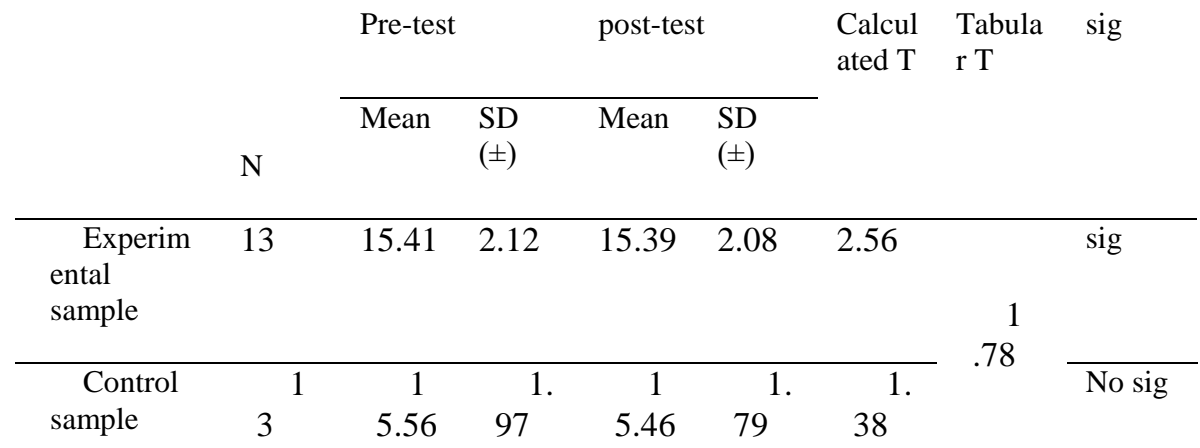

Third: Nelson Motor response (reaction speed):

Table 4. Results of the two tests for the Nelson Kinetic Response Test.

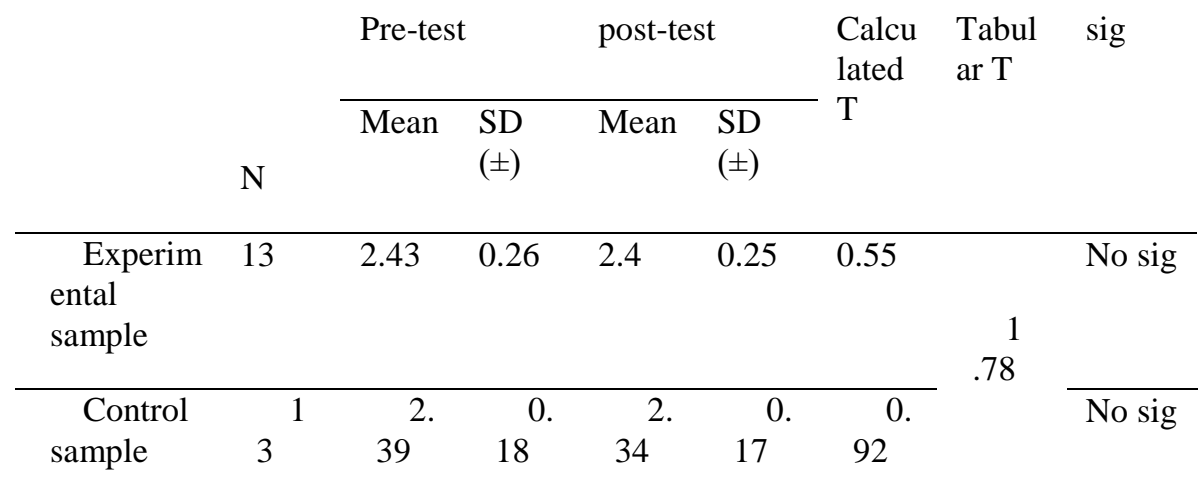




\section{Discussion}

The use of directed toys has a positive result in the improvement of some compatibility capabilities of Primary school students, and this is what we have noticed through table.02 in that there are statistically significant differences between the pre- and post-test of the experimental sample compared for all tests except Nilson's motor response test, as the This sample was applied to the proposed program using directed games, and the researchers attribute this to the positive effect of the proposed program based on the use of directed games, by focusing on the use of physical and sport activities represented by games in addition to compatibility development exercises, and the effect of indirect sensory experience in moving from the execution of motor skills during practice to the accompanying development of neuromuscular consensus, using motor activities selected in an organized manner to use directed play which helped to improve some of the students' consensual abilities, and harmony in line with what Essam Abdel-Khalek (1994) has indicated that the higher the degree of muscle nerve-muscle compatibility in an individual, the more likely it is to be achieved, the more there is harmony and harmony between the different parts of the body and its muscles in action, the better it will be to achieve specific performance, as Ahmed Al-Luqani and Amir Qureshi (1999) point out, that school activities as part of the curriculum are affected by the nature of the content and are linked to it and with it in some way. Therefore, attention needs to be paid to the content of curricula and syllabuses in schools, especially for this category.

The researchers attribute the superiority of the experimental sample over the control sample to what was taken into account when developing the program. The researchers attribute the superiority of the experimental sample over the control sample to the scientific basis of unit construction in terms of taking into account repetition, intensity and volume during training, in addition to choosing exercises that depend on changing play and directions and balance and compatibility exercises, and that these exercises were It is performed in the form of games with the use of small tools of different sizes, colours and weights, and this result is consistent with the findings of the study by Bouabsa Mohamed et al (2015) and Ben Zidan Hussein (2011) and the study by Marwa Mohamed et al (2010) on the effectiveness of the use of directed toys in improving certain abilities of compatibility of the primary school pupils under study.

The researchers also refer to the statistical differences in Tables 04 and 05 in the Running Test as 8 and the Walking Test to use a variety of activities using guided play as chain exercises by performing simple basic skills for guided games with accurate visualization of movement with increased suspense This is consistent with the physical and skill requirements of the students. In addition to improving my father's kinetic awareness factors, it helps with general compatibility, and thus the improvement of harmonic abilities helps to use these abilities in everyday life It is consistent with what Harbash Brahim and others (2016) pointed out in his study The effectiveness of teaching strategy with games in the development of some physical capacities among primary school students (6-8 years).. 
Referring to Table No. 06, we find non-significant differences in Nelson's response to kinetic response (reaction speed), which the researchers explain that improving reaction speed requires more time, which is consistent with Mohamed Hassan Allawi (1990), Bstouisi Ahmed (1999). ) And Issam Abdel-Khalek (2000) according to which always correct codified training depends on complex movements and shortens reaction time and that response time cannot be minimized, which is the time required for physiological processes and that reaction speed is one of the important and complex characteristics that require more training until it can be improved.

\section{Conclusion}

As a result, we think that the use of guided play is an important issue that has not received the attention of researchers in the sports field in its general capacity and in physical and sports activities in educational institutions in particular. Through the survey conducted by researchers within educational institutions and some field visits, it was noted that the physical and sports classes lacked the types of training that contributed to the development of the physical, professional and mental capacities of this group, which needed care and attention in the exercise of physical and sports activities. Researchers have been interested in using a training program using directed play and in learning its impact on some of the compatibility abilities of primary school students.

\section{Acknowledgements:}

I would like to sincerely thank all those who participated in this study, especially the Directorate General of Scientific Research and Technological Development DGRDST for all the assistance provided to us in carrying out this research, as well as all the researchers, professors, students, their parents, teachers, administrators and all the administrative and pedagogical staff of the schools involved in the study. 


\section{REFERENCES}

Abdel hadi N, (2004). Psychology of play and its effect on children's learning (version 1). Amman, Jordan: Dar Wael.

Othman M, Afaf O, (2013). Motor skills of children. Alexandria: Loyalty to the world of printing and publishing.

Ahmed N, G. (2010). Play and raise a child. Jordan: Enrichment House.

Ammar B, Muhammad M ,Thunaibat, (2007). Scientific research methods and methods of preparing research. Ben Aknoun, Algeria: University Press Office.

Harbach B, Mokrani D, Benzidane H (2019). A Comparison Study for the use of Mixed Training (Training with Weight and Plyometric) In the Development of the Distinctive Strength Speed as the Players of the Handball, International Journal of Physical Education, Fitness and Sports (IJPEFS)/ https://ijpefs.com/index.php/ijpefs/article/view/247.

Bensabeur M, Mokrani D, Harbach B (2020). The Physical Conditions in Educational Institutions and their Relationship with the Teaching Performance in High Schools. Acta Facultatis Educationis Physicae Universitatis Comenianae, 60(1) :75-83.

Harbach B, Mokrani D, Benzidane H , Djourdem B (2016). The Effectiveness of the Usage of the Cooperative Learning in the Development of Certain Basic Competencies in Volleyball for 15-16 Years Old Pupils. http://dergipark.org.tr/en/pub/intjscs, 4(02) :171-176.

Suhail Q, Mahdi M, (2007). Principles of statistics and social measurement. Mansoura University: Faculty of Arts.

Marwa M, S, (2010). MA thesis entitled "Effectiveness of a guided play program in the treatment of deficiencies in some aspects of cognition in kindergarten children", http://srv4.eulc.edu.eg/eulc_v5/Libraries/Thesis/BrowseThesisPages.aspx?fn=PublicDrawT hesis\&BibID $=10163090$

Abu Shun A, (2002). The effect of training uphill slopes in developing some types of speed for soccer players. Iraq: Master Thesis.

Harbach B, Djourdem B, Snouci F, (2018). The effectiveness of the teaching-by-play strategy in developing some physical and motor abilities among secondary school students, Journal of Sports El ibdaa Mesila, https://www.asjp.cerist.dz/en/PresentationRevue/316. 6(03):131-118.

Harbach B, The effect of teaching in the implicit and reciprocal methods on raising the level of physical performance in long jumping, Journal of Science and Technology for Physical and Sports Activities, https://www.asjp.cerist.dz/en/article/146. 1(10):09-28.

Benzidan H, (2011). The effect of motor games on the kinesthetic perception of the mentally retarded, capable of training. Published research. Journal of Science and Technology of Physical and Sports Activities. Algeria: Mostaganem Institute of Physical Education and Sports.

Uskan, S., \& Bozkus, T. (2019). Place of Play in Education. International Journal of Contemporary Educational Studies (IntJCES). 5 (2), 123-131

Al-Sawi N, M, Ali Zainab M, (2011). The effectiveness of visual exercises on cognitive skills, visual abilities and the level of offensive skills in handball. The Third International Conference. Developing educational curricula in the light of recent trends and the need of 
IntJSCS Brahim, and et al., Suggested educati... IntJSCS, 2020; 8(2):192-200

the labor market. Egypt. Vol 3.

Muhammad A, S, (2004). Effectiveness of a guided play program in treating deficiencies in some aspects. Egypt. Zagazig University. 